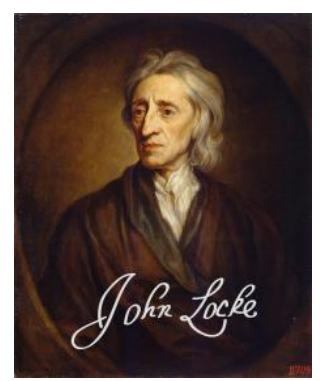

LOCKE STUDIES

Vol. 16

https://doi.org/10.5206/ls.2016.660 | ISSN: 1476-0290

Originally published: 2016

Published online: 10 FEBRUARY 2018

(C) Locke Studies, 2016

\title{
Locke on Knowledge of Existence
}

\author{
NATHAN ROCKWOOD (VIRGINIA TECH)
}

Recommended citation:

Rockwood, Nathan. "Locke on Knowledge of Existence." Locke Studies 16 (2016): 41-68.

https://doi.org/10.5206/ls.2016.660

For more information about this article:

https://ojs.lib.uwo.ca/index.php/locke/article/view/660

Locke Studies is published by The John Locke Society.

This is an open access article published under the terms of the Creative Commons Attribution-

NonCommercial-ShareAlike 4.0 International license, which permits use, distribution and reproduction in any medium, provided the original work is properly cited and shared under the original license. 


\title{
LOCKE ON KNOWLEDGE OF EXISTENCE
}

\author{
NATHAN ROCKWOOD
}

\section{\$1. The Standard Objection}

The standard objection to Locke's epistemology is that his conception of knowledge inevitably leads to skepticism about external objects. ${ }^{1}$ One reason for this complaint is that Locke defines knowledge as the perception of a relation between ideas, but perceiving relations between ideas does not seem like the kind of thing that can give us knowledge that tables and chairs exist. Thus Locke's general definition of knowledge seems to be woefully inadequate for explaining knowledge of external objects. However, this interpretation and subsequent criticism ignore a special category of knowledge Locke calls 'real knowledge', which is Locke's own account of how we can have knowledge of the real world. Rather than evaluating whether Locke's definition of knowledge in general can get us knowledge of external objects, we should instead focus our attention on whether Locke's account of real knowledge can explain how we have knowledge of external objects.

Lex Newman has taken one step in the right direction by recognizing that sensitive knowledge (i.e., knowledge from sense perception) that material objects exist is a kind of real knowledge (Newman 2004 and 2007). Perceiving a relation between ideas is necessary but not sufficient for real knowledge. According to Newman, real knowledge that a material object exists requires that, in addition to the perception of a relation between ideas, we make a probabilistic judgment that our idea of the object corresponds to a material object. It is important to Newman's interpretation, for reasons that will be explained below, that only sensitive knowledge of material objects counts as a kind of real knowledge that external objects exist. However, Locke's account

\footnotetext{
${ }^{1}$ For purposes of this paper 'external object' will be any object outside of our ideas (including ourselves, God, and material objects).
} 
of sensitive knowledge falls within the broader category of knowledge of existence; this category also includes knowledge of our own existence by intuition and knowledge of God's existence by demonstration. So Newman's interpretation of real knowledge cannot explain how, in general, Locke thinks we can have knowledge of the existence of external objects.

My proposal builds on Newman's suggestion that sensitive knowledge is a kind of real knowledge, but I show how Locke's account of real knowledge extends to all three kinds of knowledge of existence (i.e., intuitive knowledge of our own existence, demonstrative knowledge of God's existence, and sensitive knowledge that material objects exist). I take that second requirement for real knowledge to be the relation between ideas and reality, ${ }^{2}$ whereas Newman holds that it is the judgment that there is such a relation. In particular, I argue that real knowledge requires that there be a conformity between our ideas and reality. On this interpretation all three kinds of knowledge of existence count as real knowledge (whereas for Newman only sensitive knowledge counts as real knowledge). So I am able to show how, in general, Locke's account of real knowledge can give us knowledge of the existence of external objects.

The view I attribute to Locke can be called the Dual Relation View since, on this interpretation, knowledge of existence includes both the perception of one relation between ideas and a second relation between those ideas and an external object. The ideas we perceive to agree will be different in each of the three kinds of knowledge of existence. ${ }^{3}$ In each case, though, there is a

${ }^{2}$ A few commentators have taken Locke's account of sensitive knowledge to consist, at least in part, in the relation between sensation and an external object (Ayers 1991, i, 62 and 159; Bolton 2004, 304-7; Wilson 2014, 426 and 443). However, these commentators have taken this relation between an idea and an external object to apply only to sensitive knowledge, whereas I show that knowledge that we exist and knowledge that God exists also includes a relation between ideas and reality. I also argue that such knowledge counts as real knowledge.

${ }^{3}$ As I interpret Locke, in knowledge of my own existence I perceive an agreement between the idea of myself thinking and the idea of my existence (cf. note 13, below), and in demonstrative knowledge of my own existence the idea of myself thinking and 
conformity between the perceived ideas and the actual existence of an external object. It is because these ideas conform to reality that Locke thinks the perception of these ideas can give us knowledge that an external object exists. Thus Locke's account of real knowledge explains why he thinks we can have knowledge that external objects exist.

\section{§2. The Ideas-Only View}

The problem of how Locke can claim to know anything about external objects arises from Locke's official definition of knowledge:

Knowledge then seems to me to be nothing but the perception of the connexion and agreement, or disagreement and repugnancy of any of our ideas. (E IV.i.2, 525)

Locke defines knowledge as the perception of a relation (either an agreement or a disagreement) between ideas. The next section is titled 'This Agreement Fourfold' (E IV.i.3, 525). By 'this agreement' Locke means the perceived relation between ideas discussed in the prior section (E IV.i.2, 525). In order to 'understand a little more distinctly, wherein this agreement or disagreement consists', he says, 'I think we may reduce it all to these four sorts'; importantly, the fourth sort is 'real existence' (E IV.i.3, 525). Since knowledge is defined as the perception of a relation between ideas, and 'real existence' is listed as one of the perceived relations, we expect knowledge of real existence to be the perception of a relation between ideas.

But what Locke actually says defies our expectations. When he gets to the fourth sort of relation, he says:

The fourth and last sort is, that of actual real existence agreeing to any idea (E IV.i.7, 527, my emphasis)

the idea of God's existence. In sensitive knowledge that a material object exists, the idea of having a sensation agrees with the idea of an external object causing the sensation (cf. footnote 14). 
Call the fourth sort of relation described here the 'realexistence relation'. This relation appears to be a relation between an idea and an external object (an 'actual real existence'). So, contrary to our expectations, the fourth sort of relation does not appear to be a perceived relation between ideas.

One way to resolve the tension between Locke's definition of knowledge and his description of the real-existence relation is to insist that the real-existence relation is a relation between ideas. The motivation for this interpretation comes from two considerations. First, knowledge is the perception of a relation between ideas. Second, the context suggests that the realexistence relation in E IV.i.7 is that perceived relation. So when Locke describes the real-existence relation as 'actual real existence agreeing to any idea' (E IV.i.7, 527), he might mean to say that the real-existence relation is between 'the idea of real existence and the idea of any thing' (Owen 2008, part 2, my emphasis; cf. Allen 2013, 256; Nagel 2016). Call this the IdeasOnly View, since knowledge of existence consists solely in perceiving a relation between ideas.

However, even the proponents of the Ideas-Only View concede that the phrase 'actual real existence agreeing to any idea' (E IV.i.7, 527) seems to be describing a relation between an idea and an external object. David Owen says, 'The natural way to understand this is as the agreement between the thing itself (the actual real existent) and the idea of the thing' (Owen 2008, part 2). Jennifer Nagel likewise acknowledges that Locke's emphasis on 'actual' and 'real' suggests that 'actual real existence' refers to an external object rather than the idea of existence (Nagel 2016, 316). Newman reports that it is a 'widespread opinion' that the relation is 'not between two ideas, but between an idea and an actual real existence' (Newman 2007, 331). ${ }^{4}$ So they acknowledge that the most straightforward interpretation of the passage is that the real-existence relation is between an idea and an external object.

\footnotetext{
${ }^{4}$ Although Newman does not hold the Ideas-Only View, he interprets the realexistence relation in E IV.i.7 as a relation between ideas (Newman 2007, 331).
} 
Indeed, Locke uses similar language elsewhere to describe a relation between an idea and an external object. For instance, real ideas 'have a conformity' with external objects (E II.xxx.1, 372), and he argues that all simple ideas are real because they 'all agree to the reality of things' (E II.xxx.2, 372, my emphasis). In other passages he uses phrases such as 'agree to real existence' (E II.xxxii.22, section heading, 392) and 'agree with the existence of things' (E II.xxx.5, section heading, 374). ${ }^{5}$ All these passages refer to a relation between an idea and an external object. The similarity of these passages with the description of the realexistence relation as 'actual real existence agreeing to any idea' suggests that, as in those other passages, Locke is here describing a relation between an idea and an external object.

Similarly, there are other passages where Locke uses 'real existence' to refer to an external object. For example, he argues that nothing cannot 'ever produce any real existence' (E IV.x.8, 622, my emphasis). Also, he says that ideas of modes are 'made by the mind...without patterns, or reference to any real existence' (E III.v.3, 429, my emphasis), and they are 'not copies, nor made after the pattern of any real existence, to which the mind intends them to be conformable' (E II.xxxi.14, 384, my emphasis). Each of these instances of 'real existence' refers to an external object. This provides further evidence that Locke intends 'actual real existence' to refer to an external object rather than the idea of existence. So there are close textual parallels showing that 'actual real existence agreeing to any idea' describes a relation between an idea and an external object.

One might insist that, despite the strained reading of E IV.i.7, Locke's definition of knowledge commits him to the view that the perception of a relation between ideas is the one and only one condition for knowledge of existence. For he defines knowledge as the perception of a relation between ideas, and then he says: 'Where this perception is, there is knowledge; and where it is not...we always come short of knowledge" (E IV.i.2, 525). The

${ }^{5}$ cf. E II.xxxii.22, 392; III.ix.12, 482; IV.iv.3, 563; and IV.iv.18, 573. 
perception of a relation between ideas is necessary and sufficient for knowledge. It is necessary because where we do not perceive a relation between ideas 'we always come short of knowledge'; it is sufficient because where we do perceive a relation between ideas 'there is knowledge'. Given that the perception of a relation between ideas is by itself necessary and sufficient for knowledge, there is reason to think that on Locke's view there is only one requirement for knowledge of existence (cf. Soles 1985, 353).

But this interpretation ignores the category of 'real knowledge'. Locke anticipates the objection that if knowledge consists solely in the perception of a relation between ideas then we cannot have knowledge of the actual world. He imagines an objector saying:

If it be true, that all knowledge lies only in the perception of the agreement or disagreement of our own ideas, the visions of an enthusiast, and the reasoning of a sober man, will be equally certain. 'Tis no matter how things are: so [long as] a man observe but the agreement of his own imaginations...it is all truth, all certainty. (E IV.iv.1, 563, my emphasis)

He introduces real knowledge as a way to account for our knowledge of the actual world; this is his answer to the objection that the perception of a relation between ideas cannot give us knowledge 'of things as they really are' (E IV.iv.1, 563). He says:

Our knowledge therefore is real, only so far as there is a conformity between our ideas and the reality of things. (E IV.iv.3, 563, my emphasis)

The perception of a relation between ideas is necessary but not sufficient for real knowledge. In addition to the perception of a relation between ideas, real knowledge requires that there is also a conformity between our ideas and reality. Thus there are two requirements for real knowledge. Real knowledge opens up the possibility that knowledge of existence includes a second requirement, namely a conformity relation between ideas and reality. Moreover, the real-existence relation described in E IV.i.7 as 'actual real existence agreeing to any idea' might be an expression of this second requirement for real knowledge. On this 
interpretation, knowledge of real existence is a kind of real knowledge that requires both the perception of a relation between ideas and a conformity relation between ideas and reality.

Keith Allen, however, argues that knowledge of existence is not a kind of real knowledge. On his interpretation, 'real knowledge concerns the nature of things', while knowledge of existence 'concerns their existence'. He contends that Locke's chapter on real knowledge 'specifically concerns abstract general knowledge, and not particular knowledge of existence' (Allen 2013, 253). Much of the chapter concerns mathematical and moral knowledge (E IV.iv.5-10, 564-68), which is concerned with the perception of relations between abstract ideas rather than with particular existences. Similarly, much of the discussion of substance is spent debating about how to categorize changelings and monsters (E IV.iv.14-17, 569-73), indicating that in this chapter Locke is interested in types of substances. Finally, when he later discusses knowledge of existence he says, 'Hitherto we have only considered the essences of things, which being only abstract ideas, and removed in our thoughts from particular existence...gives us no knowledge of real existence at all' (E IV.ix.1, 618). Hence, Allen concludes, knowledge of existence does not appear to be a kind of real knowledge (Allen 2013, 253).

But, in reply to Allen, Locke holds that there are two kinds of real knowledge. For, according to Locke, ideas can conform to reality in two ways: 'by real ideas, I mean...such as have a conformity with real being, and existence of other things, or with their archetypes' (E II.xxx.1, 372). Some ideas represent external objects, and these ideas conform to reality by conforming to the external objects they represent. Other ideas are 'archetypes of the mind's own making, not intended to be the copies of anything, nor referred to the existence of anything' (E IV.iv.5, 564). Allen is right that the perception of the latter kind of real ideas, archetypes of the mind's own making, does not concern knowledge of existence. But the perception of the former kind of real ideas (which requires a conformity between an idea and an external object) is relevant to knowledge of existence. 
Further, on Locke's view we can have real knowledge of particular substances. In his exchange with Stillingfleet about the grounds for certain knowledge that God exists, Locke cites his account of real knowledge, which in the Essay he 'delivered in these words':

Wherever we perceive the agreement or disagreement of any of our ideas, there is certain knowledge; and wherever we are sure those ideas agree with the reality of things, there is certain real knowledge. Of which agreement of our ideas with the reality of things, I think I have shown wherein that certainty, real certainty, consists. (W4: 50, my emphasis; cf. E IV.iv.18, 573)

Locke here quotes his account of real knowledge as the grounds for our certainty that God exists. So, contrary to Allen's claim, we can have real knowledge that a particular substance exists. It appears, then, that there are two requirements for knowledge of existence.

As a final consideration against attributing the Ideas-Only View to Locke, he denies that the perception of a relation between ideas is by itself sufficient for knowing that God actually exists. Descartes, for example, argues that there is a necessary connection between the idea of God and the idea of existence, and from this he concludes that God actually exists. But on Locke's view, even if the idea of God necessarily contains the idea of existence that still would not prove that God actually exists:

Though the complex idea for which the sound God stands (whether containing in it the idea of necessary existence or no, for the case is the same) will not prove the real existence of a being answering to that idea, any more than any other idea in any one's mind will prove the existence of any real being answering that idea (W4: 55)

Showing that the idea of God is contained in the idea of existence (and thus the idea of existence is necessarily connected to the idea of God) does not prove that God actually exists. Now, Locke does think that one can give a demonstration of God's existence (E IV.x.2-6, 619-21), and a demonstration is the 
perception of a relation between a chain of ideas (cf. E IV.ii.2-3, 531-32; IV.iii.2, 539). So he does think that the perception of a relation between ideas can give us knowledge that God exists. But, given that Locke makes this criticism of Descartes' ontological argument, he cannot say that the perception of a relation between ideas is by itself sufficient for knowledge that God actually exists. Some further condition must be met (below I argue that further condition is a necessary connection between the perceived ideas and God's actual existence). The implication for the Ideas-Only View is obvious: Locke denies that perceiving a relation between ideas is by itself sufficient for knowledge that an object (such as God) exists, and hence he does not hold the IdeasOnly View.

The Ideas-Only View fails in an instructive way. One problem for the Ideas-Only View is that the real-existence relation described in E IV.i.7 as 'actual real existence agreeing to any idea' does not describe a relation between ideas; instead, it describes a relation between an idea and an external object. Thus we should reject the view, based on this misinterpretation of $\mathrm{E}$ IV.i.7, that in knowledge of existence the two ideas that are perceived to agree are the idea of the object and the idea of existence. A second problem for the Ideas-Only View is that Locke denies that knowledge of the existence of God consists solely in the perception of a relation between ideas. There must therefore be some further requirement for knowledge that an external object actually exists. Fortunately, both of these problems can be solved together by taking the real-existence relation to hold between an idea and an external object. According to the Dual Relation View, the real-existence relation described in E IV.i.7 is an expression of a second requirement for knowledge of existence: namely, an idea must be related to the actual existence of an external object. This retains the most plausible interpretation of 'actual real existence agreeing to any idea' as a relation between an idea and an external object, and it provides Locke's account of knowledge of existence with a second requirement for knowledge of existence. 
Yet the Ideas-Only View gets something important right. The definition of knowledge entails that in knowledge of existence we perceive some relation between ideas. Locke elsewhere identifies the two ideas that we perceive to be related, which again shows that knowledge of existence includes the perception of some relation between ideas. But the real-existence relation described in E IV.i.7 is not that perceived relation. The Ideas-Only View goes wrong in assuming that there is only one requirement for knowledge of existence, which leads to the implausible interpretation of 'actual real existence agreeing to any idea' as a relation between ideas. The important thing to learn here, I suggest, is that Locke's account of knowledge of existence includes two relations.

\section{§3. The Second Requirement for Real Knowledge}

Locke's account of real knowledge offers a promising direction for interpreting his account of knowledge of existence. For real knowledge is supposed to explain how it is that we have knowledge of the actual world, and knowledge of existence is knowledge about the actual world. He even indicates that knowledge that God exists is a kind of real knowledge. There are good reasons, then, for turning to Locke's account of real knowledge as a way of understanding his view on knowledge of existence.

Newman points out that Locke introduces real knowledge as a way to ensure that our knowledge of the world corresponds to the way the world actually is (Newman 2007, 333). On his interpretation, real knowledge requires that, in addition to the perception of a relation between ideas, we make a fallible judgment that our ideas correspond to an external object. He then argues that sensitive knowledge (i.e. knowledge from sensation that material objects exist) is a kind of real knowledge. He calls this the Dual Cognitive Model since sensitive knowledge includes two cognitive components: as a kind of knowledge, we perceive a relation between ideas; as a kind of probable judgment, we presume that our sensations correspond to an external object that causes that sensation (Newman 2007, 325). 
Locke takes real knowledge to be knowledge where 'there is a conformity between our ideas and the reality of things' (E IV.iv.3, 563). Newman points out that Locke uses the term 'assurance' and its cognate 'sure' to describe our epistemic status to this conformity between ideas and reality (cf. E IV.iv.3, 563 and E IV.iv.18, 573). Locke sometimes uses the term 'assurance' to refer to a kind of probable judgment (e.g. E IV.xvi.6, 662). ${ }^{6}$ So, Newman suggests, these passages imply that real knowledge includes a judgment that our ideas correspond to reality (Newman 2007, 348-49). On this view, sensitive knowledge includes both the perception of a relation between ideas and a judgment that our sensation corresponds to an external object.

One attractive feature of the Dual Cognitive Model is that it explains why Locke takes sensitive knowledge to be less certain than intuitive and demonstrative knowledge. On this model, sensitive knowledge is a kind of knowledge because it includes the perception of a relation between ideas, yet it is less certain than other forms of knowledge because sensitive knowledge includes a fallible judgment that our sensation is caused by an external object (Newman 2007, 325). So the Dual Cognitive Model can simultaneously explain why sensitive knowledge counts as knowledge and also why it is less certain than other forms of knowledge.

But this attractive feature also prevents the Dual Cognitive Model from extending to other kinds of knowledge of existence (cf. Allen 2013, 255). The Dual Cognitive Model includes a fallible judgment that an idea corresponds to an external object, and this fallible judgment is what makes sensitive knowledge less certain than intuitive and demonstrative knowledge. If this model were extended to knowledge of our own existence and knowledge of God's existence, then these items of knowledge would (like sensitive knowledge) merit only the third degree of certainty. But surely this is not Locke's intent: knowledge that we exist

\footnotetext{
${ }^{6}$ For exceptions, see E IV.i.9, 528; IV.ii.6, 533; IV.vi.10, 584; IV.x.2, 618 (cf. Owen 2008, part 3; Rockwood 2013, 21).
} 
'come[s] not short of the highest degree of certainty' (E IV.ix.3, 619, my emphasis), and we know that God exists by demonstration which is the second degree of certainty ( $\mathrm{E}$ IV.iii.21, 552 and IV.ii.2, 531); and he affirms that we are more certain that we exist and that God exists than we are that material objects exist (E IV.xi.2, 631). So knowledge that we exist and knowledge that God exists cannot include a probabilistic judgment that makes these items of knowledge less certain. Since Locke indicates that such knowledge counts as real knowledge, yet reaches the highest degrees of certainty, we have good reason to suspect that Newman has gone wrong in taking the second requirement for real knowledge to be a probabilistic judgment.

Aaron Wilson develops a similar interpretation to the Dual Cognitive Model, and his interpretation has a similar problem. Wilson argues that there are both internalist and externalist requirements for sensitive knowledge ${ }^{7}$ (in this his view resembles the Dual Relation View I am arguing for in this paper). The internalist requirements include the perception of a relation between the relevant ideas, and an assurance that our sensations are caused by external objects (Wilson 2014, 438, 443). Both of the internalist requirements are elements in Newman's Dual Cognitive Model. What Wilson adds, though (cf. Wilson 2014, p. 443), are two externalist requirements:

1. the sensation of the object must actually be caused by an external object, and

2. the sensation of an object must be a "very reliable" indicator that an object actually exists.

Wilson argues that sensitive knowledge is less certain than intuitive and demonstrative knowledge because sensation is

${ }^{7}$ Wilson characterizes the internalist-externalist distinction within Locke's framework: an internalist requirement for knowledge is 'something internal to our ideas and perceptions' that is necessary for (at least some) knowledge, whereas an externalist requirement would be 'something external to our ideas and perceptions' that is necessary for (at least some) knowledge (Wilson 2014, 426). 
merely a reliable indicator of an actual external object. On the one hand, if the sensation of an object were necessarily connected to the actual existence of an external object causing that sensation, then it would be 'unclear why...the assurance [that the object exists] is not as great as the certainty of intuitive knowledge'. On the other hand, 'the possibility of perceptual error would account for this deficiency' in our assurance that an external object actually exists (Wilson 2014, 438). So, according to Wilson, the highly reliable connection (but not necessary connection) between a sensation and an external object causing that sensation explains why sensitive knowledge is less certain than other forms of knowledge. ${ }^{8}$

Unfortunately, Wilson's interpretation cannot extend to all three kinds of knowledge of existence. On his interpretation,

Sensitive knowledge is very different from the [other degrees of knowledge] because its epistemic conditions-i.e. what Locke thinks makes it knowledge - are very different from the epistemic conditions for intuitive and demonstrative knowledge...In the case of intuitive and demonstrative knowledge, the epistemic conditions seem entirely internal; but in the case of sensitive knowledge, some of the epistemic conditions are external. (Wilson 2014, 426)

Sensitive knowledge alone has externalist conditions. So Wilson's interpretation excludes the possibility that knowledge of our own existence and knowledge of God's existence also depends on satisfying the externalist requirements for knowledge. Further, since one of the requirements is that there be a reliable (but not necessary) connection between the relevant ideas and the external object, satisfying this condition would thereby make knowledge of our own existence and knowledge of God's existence less certain than other forms of knowledge. But we have seen that the opposite is the case. Wilson's interpretation, then, cannot explain how Locke thinks we attain knowledge of all

\footnotetext{
${ }^{8}$ Martha Bolton also argues that, for Locke, the reliability of the senses gives us sensitive knowledge that external objects exist (Bolton 2004, 304-7).
} 
three kinds of knowledge of existence.

What we need is an interpretation of real knowledge that can extend to all three kinds of knowledge of existence. So the further requirement for real knowledge that an external object cannot be, as Newman contends, a probabilistic judgment that our ideas conform to reality; nor, as Wilson contends, can the externalist requirement for knowledge that an external object exist be a reliable (but not necessary) connection between the relevant ideas and the external object. Below I argue that the second requirement for real knowledge is the relation (not the judgment of the relation) between our ideas and reality, and that this relation is a necessary connection (not a merely reliable one). This interpretation can extend to all three kinds of knowledge of existence without thereby making knowledge of our own existence and knowledge of God's existence less certain. Further, it is because of this necessary connection between our ideas and reality, I will claim, that Locke thinks the perception of the relevant ideas gives us real knowledge that the object actually exists.

\section{\$4. The Dual Relation View}

In $\S 2$ above we saw that Locke's definition of knowledge entails that knowledge of existence must include the perception of a relation between ideas. Yet we also saw that he does not take the perception of a relation between ideas by itself to be sufficient for knowledge that an object actually exists. In this section I will argue that the further requirement needed for knowledge of existence is a necessary connection between the perception of the relevant ideas and the actual existence of the external object.

There are two reasons for thinking that knowledge of existence includes a relation between ideas and reality. First, the second requirement for real knowledge is the relation between ideas and reality. Locke says, 'Our knowledge therefore is real only so far as there is a conformity between our ideas and the reality of things' (E IV.iv.3, 563, my emphasis). Similarly, he says that 'this conformity between our simple ideas, and the existence of things, is sufficient for real knowledge' (E IV.iv.4, 564, my 
emphasis). ${ }^{9}$ It is the conformity relation between the idea and the external object (not the judgment of the relation) that is sufficient to make it real knowledge. While we may make a judgment that our ideas conform to reality (which explains his use of 'assurance' and its cognates), real knowledge does not consist in making this judgment. The second requirement for real knowledge, then, is that our ideas conform to reality. Knowledge of existence is a kind of real knowledge, so real knowledge requires that there be a conformity relation between the ideas and reality.

Second, Locke implies that knowledge of existence includes the real-existence relation, and he describes the real-existence relation as 'actual real existence agreeing to any idea' (E IV.i.7). As I argued above (in §2), this real-existence relation is a relation between an idea and an external object. In fact, his description of the real existence relation can be seen as an expression of the second requirement for real knowledge. He sometimes describes the relation in real knowledge as a "conformity' ${ }^{10}$ and he sometimes describes the relation as an 'agreement'. ${ }^{11}$ This is consistent with Locke's language use, since he sometimes uses 'agree' and 'conform' interchangeably. ${ }^{12}$ So the real-existence

${ }^{9}$ Locke's comment here may suggest that the perception of a relation between ideas is not necessary (since he seems to say that the conformity is by itself sufficient). But the passage does not need to be read this way. I take it that Locke is assuming that we are talking about knowledge (i.e., the perception of a relation between ideas), and a conformity of the ideas in knowledge is sufficient to make that knowledge count as real knowledge.

${ }^{10}$ E IV.iv.3, 4, 5, 8, 11, and 12 (563-68).

${ }^{11}$ E IV.iv.2 (section heading), 3, 6, 9, 12 (section heading), and 18 (563-73).

${ }^{12}$ Locke talks about 'whether the action agrees or disagrees with a rule', and then immediately rephrases this as 'either conformity or not conformity of any action to that rule' (E II.xviii.14, 358). Apparently agreeing to a rule is the same as conforming to a rule, and disagreeing with a rule is not conforming to the rule. In the next section Locke contrasts 'conformity' with 'disagreement', saying that it is an action's 'conformity to or disagreement with some rule that makes them to be...good or bad' (E II.xxviii.15, 359, my emphasis; cf. E II.xxviii.4, 350). The contrast with 'disagreement' is 'agreement', but here Locke uses 'conformity' instead. So here again Locke uses 
relation described in E IV.i.7 as 'actual real existence agreeing to any idea' can be taken as an expression of the second requirement for real knowledge: Locke is saying that we have knowledge of real existence when our ideas conform to an actual external object in the world.

There are good reasons, then, for taking knowledge of existence to include a relation between the relevant ideas and an external object. Further, the second requirement for knowledge of existence is general. For in E IV.i.7, when Locke describes the relation included in knowledge of existence as 'actual real existence agreeing to any idea', he is specifying a requirement for knowledge of existence that applies to all three kinds of knowledge of existence (rather than applying uniquely to sensitive knowledge). So while Wilson was right to see Locke having an externalist requirement for sensitive knowledge, he was wrong to limit that externalist requirement to only sensitive knowledge; for both intuitive knowledge of our own existence and demonstrative knowledge of God's existence include a conformity relation between the relevant ideas and the actual existence of the external object.

It is not yet clear, however, what Locke means by 'conformity'. Intuitively, we might take 'conformity' to mean 'resemblance'. But, on Locke's view, ideas can conform to an external object without resembling the external object (E II.xxx.2, 372-73). A simple idea of a secondary quality does not resemble a quality in an external object, but the idea does represent an actual power in the external object (namely, the power to produce that idea). The 'reality' of simple ideas lies 'in that steady correspondence' they have to the actual qualities of external objects (whether those ideas correspond to a quality that

\footnotetext{
'agreement' and 'conformity' interchangeably. He does the same thing in his discussion of real knowledge. Locke says that in real knowledge "there is a conformity between our ideas and reality of things", and then follows this comment by saying that there are "two sorts of ideas that we may be assured agree with things" (E IV.iv.3, 563, my emphasis). So Locke here uses "conformity" and "agree" interchangeably to describe the same relation.
} 
resembles the idea, or the ideas correspond to a power to cause the idea). We have reason to believe that simple ideas 'conform' to an external object, not because the ideas resemble the external object, but because there is a necessary connection between the sensation of a simple idea and the (power of an) external object.

Locke holds that there is a necessary connection between simple ideas of sensation and an external object causing that sensation. He argues, for example, that 'since the mind...can by no means make to itself' simple ideas, these ideas 'must necessarily be the product of [external] things operating on the mind' (E IV.iv.4, 563-64; cf. II.xxx.2, 373). The sensation of a simple idea must be caused by an external object. 'From whence it follows that simple ideas are not fictions of our fancies', but are real ideas that conform to 'things without us'. So the reason he thinks that our simple ideas conform to reality is that, in his view, there is a necessary connection between the idea and an external material object. Similarly, he argues that in sensation the ideas of objects 'force themselves upon me, and I cannot avoid having them. And therefore it must needs be some exterior cause, and...some objects without me, ...that produces those ideas in my mind' (E IV.xi.5, 632, my emphasis). The idea of an object given in sensation thus has a necessary connection to an actual external material object. So, for the same reason that sensation of a simple idea counts as a real idea (namely, its necessary connection to an external object), the idea of an object taken from experience and sensible observation counts as a real idea (cf. E IV.iv.12, 568569). It appears, then, that a necessary connection between an idea and an external object is a sufficient condition for making that idea conform to reality, and thus capable of providing us with real knowledge.

The necessary connection between simple ideas of sensation and external objects also holds for ideas of reflection and a thinking substance. Speaking of both 'simple ideas, conveyed in by the senses' and of ideas from 'reflection on [the mind's] own operations', Locke says, 'Because...not imagining how these ideas can subsist by themselves, we...suppose some substratum, wherein they do subsist, and...which therefore we call substance? 
(E II.xxiii.1, 295; cf. E II.xxiii.5, 297-98). Locke's ontology prohibits the existence of bare powers unsupported by a substance. So if we have the sensation of an object, there must be a power external to us that is causing that sensation, and that power must subsist in a substance. Similarly, if we have an idea of the mind acting, there must be a power to perceive that idea, and this power must subsist in a substance. The connection here is between an idea and an actual thinking substance. From his ontology, then, it appears to follow that there is a necessary connection between the idea we have of ourselves thinking and our actual existence.

Further, Locke also takes there to be a necessary connection between the ideas of reflection and God's existence. In knowledge of God's existence we perceive a 'necessary agreement and connexion' between the 'idea of thinking' and 'the idea of the existence of an external, thinking Being' (W4: 60). The perception of the idea of ourselves thinking entails that we actually exist, since there is a necessary connection between this idea and our actual existence. Further, via the cosmological argument, Locke holds that our actual existence is necessarily dependent on God's actual existence. It follows that there is a necessary connection between the idea of thinking and God's actual existence.

The above discussion provides textual evidence for the Dual Relation View in two important ways. First, in each case of knowledge of existence there exists a necessary connection between the relevant ideas and the external object. This is desirable for an interpretation since Locke implies that the realexistence relation, which is a relation between an idea and an external object, is included in all three kinds of knowledge of existence. Second, above we saw that a necessary connection between an idea and an external object is sufficient to make that idea 'conform' to reality, and thus capable of providing us with real knowledge. Real knowledge also requires a conformity to reality. So there is good reason to think that, in addition to the perception of a relation between the relevant ideas, the necessary connection between those ideas and the actual existence of the 
external object are sufficient for real knowledge that the object exists.

It is this necessary connection between our ideas and reality that helps explain why, on Locke's view, the perception of a relation between ideas can secure knowledge of existence. For example, in knowledge of our own existence, the idea of ourselves thinking is necessarily connected to our actually thinking, and our actually thinking is necessarily connected to our actually existing. So it necessarily follows from the perception of the relation between the idea of ourselves thinking and the idea of our actual existence that we actually exist. ${ }^{13}$ It is because the perception of these ideas necessarily entails our actual existence, I suggest, that Locke thinks the perception of these ideas gives us real knowledge of our actual existence. A similar explanation can be given for knowledge of our God's existence, except that the idea of ourselves thinking is necessarily connected to God's actual existence; and given the necessary connection sensation has to an external object, the perception of the relation between the sensation and another idea ${ }^{14}$ can give us knowledge of the existence of material objects.

${ }^{13}$ Stillingfleet objected that Locke could not prove that 'spiritual substance' exists (W4: 32). Locke replies, 'I think it may be proved from my principles, and I think I have done it'. He then gives a recapitulation of a proof that seems to be his account of how we know that we exist:

First, we experiment in ourselves thinking. The idea of this action or mode of thinking is inconsistent with the idea of self-subsistence, and therefore has a necessary connexion with a support or subject of inhesion: the idea of that support is what we call substance; and so from thinking experimented in us, we have proof of a thinking substance in us... (W4: 32-33, my emphasis)

I suggest that an underlying assumption in this passage is that we perceive a necessary connection between the idea of ourselves thinking and the idea of our existence; the claim that the idea of thinking is inconsistent with the idea of selfsubsistence is a different description of this necessary connection. On this interpretation, the two ideas that give us knowledge that we exist are the idea of ourselves thinking and the idea of our own existence.

${ }^{14}$ In many passages Locke asserts that knowledge that material objects exists depends on current sense perception of that object (e.g., E IV.iii.5, 539; IV.xi.1, 630; IV.xi.9, 635; and IV.xi.13, 638). Yet Locke elsewhere identifies 'the two ideas' we 
In general, real knowledge of existence has the following form: we perceive a relation between ideas and these ideas have a necessary connection to the actual existence of an external object; so the perception of the relation between these ideas necessarily entails the actual existence of an external object. Since the perception of the relation between these ideas entails that the external object exists, Locke might reasonably claim that the perception of the relation between these ideas gives us knowledge that the external object actually exists.

The Dual Relation View marks a significant advance over Newman's Dual Cognitive Model and Wilson's interpretation. As we saw above, both these interpretations are specific to sensitive knowledge, and the additional requirement (beyond the perception of a relation between ideas) is said to make sensitive knowledge less certain than intuitive and demonstrative knowledge. But for this very reason these interpretations cannot explain how, in general, we have knowledge of existence, which includes intuitive knowledge that we exist and demonstrative knowledge that God exists. By contrast, on my interpretation the further requirement for real knowledge that an object exists is that (in addition to the perception of a relation between the relevant ideas) there be a necessary connection between those ideas and the actual existence of the external object, thus guaranteeing that the ideas 'conform' to reality in such a way as to give us real

perceive to agree in sensitive knowledge as 'the idea of actual sensation (which is an action whereof I have a clear and distinct idea) and the idea of actual existence' (W4: 360, my emphasis). The 'idea of actual sensation' is the idea of the mind having a sensation, as indicated by the parenthetical remark that the sensation 'is an action' (rather than the representation of an object). For attempts to fit Locke's account of sensitive knowledge into his between-ideas conception of knowledge, see Newman 2004 and 2007, Allen 2013, Rockwood 2013, and Nagel 2016. For dissenting views see, for example, Gibson 1917, 166; Aaron 1971, 240; Pappas 1998, 288; and Jolley $1999,187$.

The important point for the purposes of this paper is that sensitive knowledge (somehow) results from sensation, and Locke might reasonably take sense perception of an object (along with the perception of its relation to another idea) to be the source of knowledge of material objects since, on his view, the perception of this sensation (and its relation to another idea) entails that the actual existence of the external object causing that sensation. 
knowledge. Satisfying this second requirement does not make an item less certain. For it is because of this second requirement that Locke thinks that we can be certain, from the perception of our ideas, that the object actually exists. For this reason the Dual Relation View can, but these other interpretations cannot, explain how we acquire all three kinds of knowledge of existence.

In this section I have argued that there is good textual evidence that Locke holds the Dual Relation View. First, his definition of knowledge entails that knowledge of existence include the perception of a relation between ideas (and he identifies the two ideas in each case); second, his description of the real-existence relation and his account of real knowledge imply that the second condition for knowledge of existence is a connection between the relevant ideas and the actual existence of the external object. I have suggested that a necessary connection satisfies this second requirement. Beyond the direct textual evidence, one virtue of this interpretation is that it explains why Locke thinks that the perception of a relation between ideas can give us knowledge that an external object exists. It is because the relevant ideas are necessarily connected to reality that he thinks that the perception of these ideas can give us knowledge of objects in the actual world. Finally, an interpretive advantage that the Dual Relation View has over competing interpretations is that it can extend to all three kinds of knowledge of existence, whereas these competing interpretations cannot. I take it, then, that there are good reasons for attributing the Dual Relation View to Locke.

\section{\$5. Objections and Replies}

One worry about the Dual relation View is that it cannot explain why sensitive knowledge is less certain than other forms of knowledge. Newman and Wilson both appeal to the further requirement for sensitive knowledge to explain why it is less certain. However, since on the Dual Relation View all three kinds of knowledge of existence satisfy the second requirement for real knowledge, this second requirement cannot be what explains why sensitive knowledge is less certain. This leaves me with a need, then, to explain why Locke takes sensitive knowledge to be less 
certain. For an inability to provide such an explanation might be taken as evidence that sensitive knowledge does not share the same general structure as other instances of knowledge of existence.

Newman takes the degrees of certainty to be determined by 'the relative likelihood of error' (Newman 2007, 324). Intuitive knowledge 'infallibly determines the understanding' (E IV.xv.5, 656) and 'there is no room for any the least mistake or doubt' (E IV.xvii.15, 684). In knowledge from demonstration, however, 'the danger of the mistake is greater' (E IV.xvii.15, 684). For example, when we do each step of a mathematical proof correctly we have certain knowledge of the conclusion. But we are fallible, and so we may make a mistake in one or more steps of the proof, in which case the mathematical demonstration does not succeed in giving us knowledge of the conclusion (cf. E IV.xvii.15, 684). On this interpretation, if the likelihood of making an error is greater in sensitive knowledge than in demonstrative knowledge, then sensitive knowledge is less certain. While Newman takes the inclusion of a probable judgment to explain why sensitive knowledge is more likely to err than demonstration, there may be another explanation consistent with the Dual Relation View.

The unique feature of sensitive knowledge is that it depends on having a current sensation. We can know that a particular man exists, for example, when and only when we are currently perceiving him (E IV.xi.9, 635). So one of the two perceived ideas in sensitive knowledge must be the sensation of the object. Locke seems to identify the other idea as the idea of having a sensation (i.e., an idea of reflection, or our noticing that we are having a sensation). ${ }^{15}$ On this interpretation, we have sensitive knowledge when we have the sensation of an object (one idea) and we perceive that we are having a sensation (the second idea). Yet on Locke's account noticing the operations of our minds, such as perceiving that we are having a sensation, requires that we turn our minds inward. For 'unless he turns his thought'

\footnotetext{
${ }^{15}$ See footnote 14
} 
inward to the operations of the mind, 'and considers them attentively', then 'he will have but a confused idea' of those operations (E II.i.7, 107). Inattention, then, will prevent us from noticing that we are having a sensation. Yet 'he that contemplates the operations of his mind, cannot but have plain and clear ideas of them' (E II.i.7, 107). So, if we are paying sufficient attention, 'When we see, hear, smell, taste, feel, meditate, or will any thing, we know that we do so' (E II.xxvii.9, 335). From this we can see that the connection between ideas in sensitive knowledge is there, but it can be easily missed if we are not paying sufficient attention.

The fact that we may not notice the operations of our minds opens up the possibility for error in sensitive knowledge. For to have sensitive knowledge, on this interpretation, requires identifying a sensation as a sensation. This can go wrong in two ways: we can fail to identify an idea as an idea of sensation, and we can mistakenly identify an idea as a sensation when it is not. If the likelihood of making these types of errors is greater than making errors in a demonstration then, given Newman's interpretation of the degrees of certainty, sensitive knowledge would be less certain than demonstrative knowledge. Further, this explanation is consistent with the Dual Relation View. On this view, any actual sensation is necessarily caused by an external object. But we might be wrong that this particular idea is caused by an external object, and such a case we would fail to have sensitive knowledge.

The worry under consideration is that since on the Dual Relation View all three kinds of knowledge of existence satisfy the second requirement for real knowledge, there would be no explanation available to the Dual Relation View for explaining why sensitive knowledge is less certain than other forms of knowledge. But I have shown that there is at least one such explanation (consistent with Newman's own interpretation of the degrees of certainty), and there may be others. It is simply not the case, then, that the Dual Relation View is unable to explain why sensitive knowledge is less certain than other forms of knowledge. 
There is a second, related objection to the Dual Relation View. If there is a necessary connection between sensation and the external object causing that sensation, that seems to leave little room for perceptual error. But Locke surely would have recognized the possibility of perceptual error (Lolordo 2008, 707-8). Hence, goes the objection, Locke cannot have seriously thought that there is a necessary connection between sensation and an external object. Surely he would recognize that sensation is, at best, reliably (but not infallibly) connected to reality. On the interpretation just presented, however, there is a possibility of error consistent with the Dual Relation View. Specifically, if we are not paying attention to the operations of our minds we may wrongly identify an idea as a sensation when it is not, and thus take ourselves to have sensitive knowledge when we do not. Suppose, for example, we perceive an object, but it is merely a hallucination. If we take the idea of this object to be a sensation then we might think we have sensitive knowledge when we do not. The Dual Relation view, then, is consistent with our sometimes getting things wrong concerning the existence of external objects.

Another objection to the Dual Relation View is that we cannot ever know that the second requirement for knowledge of existence is satisfied. The second requirement is that there be a conformity relation between an idea and an external object. Since we cannot directly perceive an external object (only the idea of the object), ${ }^{16}$ we cannot perceive the conformity relation between an idea and an external object. Thus we cannot know that the second requirement for real knowledge of existence is satisfied. But if we cannot know that the second requirement for knowledge of existence is satisfied, goes the objection, then we cannot know that the external object exists.

However, the Dual relation View does not require that we know that we satisfy the second requirement for real knowledge. Requiring that we know that we satisfy the second requirement

${ }^{16}$ See E I.i.8, 47; IV.i.1, 525; and IV.xxi.4, 720-721. 
for real knowledge would amount to a third requirement for real knowledge, and there is no textual evidence that Locke accepts this third requirement. This makes the second requirement for knowledge a kind of 'externalist' requirement for knowledge. On an externalist view, we do not need to have justification that we satisfy the requirements for knowledge, nor do we even need to be aware that we satisfy those requirements, in order to have knowledge; merely satisfying the requirements is enough for knowledge. The second requirement for knowledge of existence is an externalist requirement of this sort.

Consider, for example, Alvin Goldman's causal theory of knowledge. On this view we have knowledge that the table we see exists if there is a causal chain that starts with the table causing our sensation of it and ending with our belief that there is a table (Goldman 1967). We do not need to know that this causal chain obtains in order to know that the table exists; simply satisfying the requirement that there is such a causal chain (whether we are aware of this fact or not) is enough for us to have knowledge that the table exists. We might go on to discuss what justification we have or arguments we can give for the claim that the table causes our sensation, but it is not necessary for knowledge that the table exists that we go on to do so. In a similar way, on Locke's view we do not have to know that our ideas conform to reality in order to meet the requirements for knowledge of existence, and thus have knowledge that an external object exists. Locke can and does give reasons for why we should think that our ideas conform to reality (see section $\S 4$ above), but this discussion is above and beyond what is required for knowledge that an external object exists. So, contrary to the objection under consideration, on Locke's view we can have knowledge that an external object exists without knowing that the second requirement for real knowledge is satisfied.

Some may find the Dual Relation View unattractive precisely because we cannot know that the second condition is satisfied. However, consider Locke's view without the second requirement for knowledge of existence. If we eliminate the second requirement for knowledge of existence, then we are left with the 
Ideas-Only View which takes the one and only one requirement for knowledge of existence to be the perception of a relation between ideas. But it seems possible for us to perceive the relation between the relevant ideas without the object actually existing. In this case we would satisfy the requirements for knowledge of existence, and so 'know' that the external object exists, even when the external object does not actually exist! This is seriously problematic. Knowledge that an external object exists should depend on the actual existence of that object. Moreover, the only relation in knowledge as such, on this view, is the relation between the ideas. So even if the object did happen to exist, on the Ideas-Only View the knowledge that the object exists, as such, bears no relation to the actual existence of the object. So failing to include the second requirement for knowledge of existence would make Locke's view more problematic. By contrast, if we include the second requirement for knowledge of existence then it is impossible to 'know' that an external object exists when it does not actually exist, since the second requirement is a necessary connection between the idea and the actual external object. From a philosophical point of view, then, Locke's view appears to be more plausible with the second requirement for knowledge of existence than without it.

The primary aim of this paper has been to argue that Locke holds the Dual Relation View. That is, Locke holds that knowledge of existence is a kind of real knowledge that includes both the perception of a relation between ideas and a conformity relation between those ideas and reality. I have also argued that he takes there to be a necessary connection between the relevant ideas and the actual existence of an external object, and that this necessary connection is sufficient for the ideas to 'conform' (in Locke's sense) to reality. This necessary connection then explains why he thinks that that the perception of a relation between the relevant ideas gives us knowledge that the external object actually exists. For when we perceive the relation between these ideas, the corresponding external object must actually exist.

So will the Dual Relation View I am attributing to Locke satisfy the skeptic about the external world? Certainly not. The 
skeptic will deny, for example, that there is a necessary connection between the sensation of an object and the actual existence of that object. However, my goal has not been to satisfy the skeptic. Instead, my goal has been to show why Locke thinks that his account can explain how we have knowledge of the existence of external objects. The reason he thinks we can know that external objects exists by perceiving relations between ideas, I have argued, is that the perception of the relevant ideas necessarily entails that the external object exists. This account satisfies Locke's definition of knowledge as the perception of a relation between ideas yet, at least on his own terms, is connected to reality in such a way that can explain how we know that an external object actually exists. ${ }^{17}$

Virginia Tech

${ }^{17}$ I owe many thanks to Samuel Rickless for comments on previous drafts of this paper. I also thank Steve Lookner, Lex Newman, Donald Rutherford, Greg Taylor, and Eric Watkins, for their comments, as well as my audiences at Brigham Young University, the UCSD History of Philosophy Roundtable, and the Berkeley-StanfordDavis Graduate Conference.

\section{REFERENCES}

Aaron, Richard I. John Locke, 3rd ed. Oxford: Oxford University Press, 1971.

Allen, Keith. 'Locke and Sensitive Knowledge', Journal of the History of Philosophy 51, 2 (2013): 249-66.

Ayers, Michael. Locke: Epistemology and Ontology. 2 vols. London: Routledge, 1991.

Bolton, Martha Brandt. 'Locke on the Semantic and Epistemic Roles of Simple Ideas of Sensation', Pacific Philosophical Quarterly 85, 3 (2004): 301-21.

Gibson, James. Locke's Theory of Knowledge and its Historical Relations. Cambridge: Cambridge University Press, 1917.

Goldman, Alvin I. 'A Causal Theory of Knowing', The Journal of Philosophy 64, 12 (1967): 357-72. 
Jolley, Nicholas. Locke: His Philosophical Thought. Oxford: Oxford University Press, 1999.

Locke, John. An Essay Concerning Human Understanding, ed. Peter H Nidditch. Oxford: Clarendon Press, 1975. [abbreviation: E]

Locke, John. The Works of John Locke in ten volumes. London: Rivington, 1824, vol. 4. [abbreviation: W4]

Lolordo, Antonia. 'Locke's Problem Concerning Perceptual Error', Philosophy and Phenomenological Research 77, 3 (2008): 705-24.

Nagel, Jennifer. 'Sensitive Knowledge: Locke on Skepticism and Sensation', A Companion to Locke, ed. Matthew Stuart. Oxford: Basil Blackwell, 2016, 313-33.

Newman, Lex (2004), 'Locke on Sensitive Knowledge and the Veil of Perception-Four Misconceptions', Pacific Philosophical Quarterly 85, 3 (2004): 273-300.

Newman, Lex. 'Locke on Knowledge'. In The Cambridge Companion to Locke's "Essay Concerning Human Understanding”, ed. Lex Newman Cambridge: Cambridge University Press, 2007, 313-51.

Owen, David. 'Locke on Sensitive Knowledge'. Unpublished paper, 2008, available at David Owen's papers:

http://www.ic.arizona.edu/ic/dwo/David\%27s\%20Papers/papersind.htm

Pappas, George. 'Epistemology in the Empiricists', History of Philosophy Quarterly 15, 3 (1998): 285-302.

Rockwood, Nathan. 'Is Sensitive Knowledge “Knowledge'?' Locke Studies 13 (2013): 15-31.

Soles, David E. 'Locke's Empiricism and the Postulation of Unobservables', Journal of the History of Philosophy 23, 3 (1985): 339-69.

Wilson, Aaron. 'Locke's Externalism about 'Sensitive Knowledge', British Journal of the History of Philosophy 22, 3 (2014): 425-45. 